\title{
Possibilidades da Filosofia, História e Sociologia da Ciência para superação de uma concepção prática-utilitária da educação científica: caminhos a serem percorridos
}

\author{
Wellington Pereira de Queirós \\ Antônio Fernandes Nascimento Júnior \\ Daniele Cristina de Souza
}

\section{Resumo}

O objetivo deste ensaio teórico é discutir sobre a seguinte questão: Por que a Filosofia, História e Sociologia da Ciência podem contribuir para a superação de um ensino de Ciências prático-utilitário? Para fundamentarmos uma possível resposta a esta questão, utilizaremos o referencial da pedagogia histórica-crítica, cujas principais categorias desenvolvidas são: humanização, apropriação, objetivação, alienação, gênero humano e indivíduo para-si. Defendemos uma abordagem em que a História, Filosofia e Sociologia da Ciência articulem as perspectivas internalista e externalista no processo de ensino-aprendizagem. Sendo assim, ao tratar um episódio científico é necessário propiciar ao indivíduo o entendimento dos aspectos lógicos, metafísicos e, ao mesmo tempo, os interesses ideológicos e as formas de expressão de cultura que formaram os sistemas científicos.

Palavras-chave: Ensino de Ciências, História, Filosofia e Sociologia da Ciência, Pedagogia Histórico Crítica.

\begin{abstract}
Possibilities of Philosophy, History and Sociology of Science for overcoming of Science Education Practical Utilitarian Conception: routes to be followed

The objective of this theoretical essay is discussing the following question: Why the philosophy, history and sociology of science can contribute to the overcoming of a science education practical-utilitarian conception? To substantiate a possible answer to this question will us use the reference of historical-critical pedagogical perspective whose main categories developed are: humanization, appropriation, objectification, alienation, and individual-for itself. Thus, we advocate an approach in which the History, Philosophy and Sociology of Science articulate the Internalism and Externalism perspectives in the teachinglearning process. Therefore, to treat a scientific episode is necessary to provide the scientific understanding of individual aspects logical, metaphysical and at the same time about the ideological interests and forms of expression of culture that formed the scientific systems.
\end{abstract}

Key words: Science Education; Philosophy, History and Sociology of Science; historical-critical pedagogical perspective 


\section{Introdução}

As revoluções que ocorreram na humanidade de ordem política ou econômica, tais como a Revolução Francesa e a Revolução Industrial, sempre vieram acompanhadas de revoluções científicas e tecnológicas. Em paralelo a essas mudanças econômicas dos modos de produção capitalista, a educação também vem sofrendo transformações. O conhecimento e a informação passam a constituir força produtiva direta no modo de produção capitalista atual.

As novas tecnologias e as mudanças na produção de bens e serviços, que caracterizam as transformações da sociedade contemporânea, têm colocado a escola diante de um grande desafio: possibilitar aos estudantes a participação no mundo de forma crítica e transformadora.

As reformas educacionais ocorridas nos últimos anos no Brasil procuraram trazer alternativas para uma educação de qualidade, o que é representada pela LDB/96 (Lei de Diretrizes e Bases da Educação Nacional). Como forma de contemplar tais diretrizes, surgem, como documentos curriculares oficiais, as Diretrizes Curriculares Nacionais para o Ensino Médio (DCNEM), os Parâmetros Curriculares Nacionais (PCNs) e suas orientações complementares $(\mathrm{PCN}+)$ que fornecem orientações para a implantação da reforma nos diferentes níveis de ensino, assim como as Diretrizes Nacionais para a formação de professores. Os DCNEM são obrigatórios, expressando a própria $\mathrm{LDB} / 96$, já os $\mathrm{PCN}$ e $\mathrm{PCN}+$ constituem um referencial teórico-metodológico para a implementação da lei nas salas de aula (RICARDO; ZYLBERSZTAJN, 2008).

As DCNEM e os PCN institucionalizaram o discurso das competências e das habilidades no sistema educacional nacional. Além disso, há uma ênfase do papel da escola na formação dos sujeitos para as necessidades do mundo do trabalho, articulando-se a ideia de formação de competências à lógica posta pela economia (RICARDO; ZYLBERSZTAJN, 2008).

Embora não haja uma total identidade em tais documentos nos sentidos construídos sobre o mundo de trabalho, sobre as competências e habilidades, interdisciplinaridade e contextualização (RICARDO; ZYLBERSZTAJN, 2008), tal perspectiva favorece uma leitura cuja concepção de ensino reduz a uma reprodução prática-utilitária dos saberes conquistados pelo homem ao longo da história da humanidade.

Tais políticas públicas, mesmo não sendo totalmente compreendidas e realizadas pelos professores nas escolas (RICARDO; ZYLBERSZTAJN, 2008), representam uma tendência da escola pública vinculada a propósitos da sociedade capitalista. Esta escola é caracterizada por Alves (2006) como manufatureira e com conteúdos empobrecidos, representados pelos manuais didáticos que privam os estudantes da vitalidade científica e cultural, com apropriação de conhecimentos incapazes de permitir uma compreensão sobre a sociedade e sua inserção nela.

Do ponto de vista dos conhecimentos, a escola atual, com raras exceções, promove um ensino de Ciências com a apresentação de leis e conceitos que não têm significados no cotidiano 
do educando e nem é capaz de desenvolver nos estudantes uma formação sociocultural mais abrangente, ou seja, do não cotidiano para que o indivíduo possa desenvolver uma crítica maior do sistema político e econômico no qual ele vive. O conhecimento científico é imposto como se fosse um produto pronto e acabado, ao passo que deveria ser mostrado como um processo em desenvolvimento influenciado por fatores econômicos, políticos e sociais, passível de novas descobertas e revoluções.

Diante da problemática exposta acima, tudo indica que o ensino escolar reproduz as relações de dominação, contribuindo para o aumento de uma sociedade alienada. Assim, se fizéssemos a pergunta: "Para que serve aprender isto?", muitos estudantes, com uma visão mecanicista e utilitária do saber, diriam que serve para passar no vestibular, arranjar um emprego; outros, de uma forma mais pessimista, diriam que não serve para nada. E os professores em muitas situações ficariam sem resposta, ou simplesmente responderiam que serve como requisito para aprender outro conteúdo, para aplicar no trabalho dos estudantes, para melhorar as condições de vida, ou porque faz parte do cotidiano do estudante etc. Parece razoável pensarmos em tais respostas, porque estamos engendrados em uma sociedade alienada, na qual o prático e utilitário sem reflexões adquirem valor.

No caso específico do Brasil, os documentos oficiais como os Parâmetros Curriculares Nacionais utilizam-se do discurso de uma educação crítica e reflexiva e propõe uma educação científica subsumida ao mundo do trabalho (SILVA; LOPES, 2007). Mas, será que ensinar um determinado saber científico para servir apenas ao cotidiano ou ao mundo do trabalho do estudante vai torná-lo crítico e reflexivo no seu mundo? A resposta para tal pergunta dependerá dos objetivos da educação científica. Sendo assim, o que fazer? Repensar os objetivos da educação no Brasil? Por tais questionamentos é que propomos como questão de reflexão nesta comunicação a seguinte pergunta: Por que a Filosofia, História e Sociologia da Ciência podem contribuir para a superação de um ensino de Ciências prático-utilitário?

\section{A Pedagogia Histórico-Crítica: A visão do Homem como um Ser Histórico-Social}

As características genéticas do homem é um dos fatores que o diferencia das outras espécies do reino animal, isso se pensarmos em uma visão meramente biológica; entretanto, é o trabalho que distingue o homem das outras espécies animais. Os animais se adaptam à realidade natural tendo sua existência garantida naturalmente, enquanto o homem precisa produzir sua própria existência, e para isto ele age num processo de transformação da natureza que é feito por uma ação pensada, planejada para atingir finalidades: o trabalho. Portanto, a diferença fundamental do homem em relação aos outros animais é o trabalho, que é visto nesta perspectiva 
como uma ação em que o homem busca se apropriar dos recursos da natureza para seu próprio benefício (SAVIANI, 2003).

O Homo sapiens sapiens se torna humano historicamente numa relação entre si e com a Natureza. Assim, cada período da história da humanidade, a Pré-História, Idade Média, Renascimento, Idade Moderna foram caracterizados por diferentes expressões da interferência do homem na natureza e desta sobre ele. Nestes sucessivos períodos, o homem se apropriou e objetivou da matéria, dos saberes, de valores morais e éticos de formas diferentes construindo a sua história social (SAVIANI, 2003).

O enfoque do presente ensaio se refere a um produto dessa relação: os saberes, os quais permitem ao humano pensar e mediar suas ações no mundo, sendo este resultado de um trabalho não-material, fundamento de base para a educação. Os saberes são entendidos como produção social, esta concepção auxilia na compreensão, numa perspectiva crítica, sobre a visão prático-utilitária do saber, cujo enfoque principal procura olhar as suas apropriações pelos sujeitos.

Um espaço institucionalizado para a apropriação destes saberes é a escola, a qual tem como função fornecer instrumentos para que os sujeitos adquiram os saberes elaborados e também os próprios rudimentos destes saberes. Infelizmente, na maioria das vezes, esses saberes são ensinados como se fossem construídos de forma neutra e como um produto pronto e acabado; tal perspectiva contribui para a formação de um indivíduo desumanizado e alienado na sociedade. Deste modo, o referencial da pedagogia histórico-crítica pode contribuir para fazermos uma reflexão e buscarmos formas de superação dessa realidade, pois, para essa corrente de pensamento a educação pode transformar as condições sociais dos indivíduos em uma sociedade, por meio do entendimento de que o conhecimento é uma produção histórico-social.

Assim, para fundamentarmos uma possível resposta à pergunta da presente comunicação enunciaremos as principais categorias desenvolvidas por este referencial que são primordiais para o entendimento do indivíduo como um ser histórico-social e sua relação com os saberes. Segundo Duarte (2001) estas categorias são: objetivação, apropriação, humanização, alienação, gênero humano, indivíduo para si. Estas categorias são primordiais para uma teoria de formação do indivíduo no paradigma histórico-social. Vejamos o significado de cada uma delas:

Apropriação e Objetivação: Segundo Duarte (2001) o homem se apropria da matéria natural e ao transformá-la produz condições para sua existência. Essa transformação é fixada no objeto e desta forma a realização do trabalho constitui-se na sua objetivação. Essa apropriação e objetivação unem-se dialeticamente gerando no homem novas necessidades e conduzindo a novas formas de ação, num constante movimento de superação por incorporação. Neste processo de apropriação e objetivação acontece a humanização. 
A humanização pode ter caráter alienante ou libertador. Esse caráter influencia na formação do indivíduo conforme a condução da apropriação. Segundo Duarte (2001) a humanização progride na medida em que a atividade social e consciente dos homens produz objetivações que tornam possível uma existência humana cada vez mais livre e universal.

O problema é que sob as relações de dominação isso se torna difícil, pois o trabalho de milhões de seres humanos tem possibilitado que objetivações humanas como a ciência e a produção material gerassem, no século passado e no presente, alternativas de existência livre e universal sem precedentes na história humana, mas isso tem se realizado de forma contraditória, pois essas possibilidades têm sido geradas à custa da miséria, da fome, da degradação ambiental, da ignorância e morte de milhões de pessoas. Para Giardinetto (1999), estas relações sociais de dominação podem conduzir o homem à alienação. Nesta perspectiva o homem é visto como um objeto de produção dentro da sociedade capitalista.

As relações sociais por meio da apropriação e objetivação formam o gênero humano que é diferente das características genéticas transmitidas ao longo das gerações e dependendo do tipo de relação social pode ser humanizador ou alienante. Quando o indivíduo no processo de apropriação e objetivação busca superar as formas de alienação do gênero humano na sua interação com o meio social, este indivíduo é classificado, no referencial da pedagogia históricocrítica, como indivíduo para si. De acordo com Duarte (2001, p.29) "a formação do indivíduo para si é a formação do indivíduo como alguém que faz da sua vida uma relação consciente com o gênero humano." Assim, para Duarte $\left(2001^{1}\right.$, p.30) o objetivo dessa categoria é:

"Nosso objetivo é o de que essa categoria possa ser ponto de referência para que as análises da formação da individualidade humana, sob as relações sociais de dominação, não se restrinjam à necessária, porém insuficiente, caracterização das formas alienadas de individualidade, mas situe essa caracterização no interior de uma abordagem mais ampla (fundamental na relação entre objetivação e apropriação e na relação entre humanização e alienação) do vir-a-ser possivel da individualidade humana. Esperamos que a compreensão dessa categoria contribua para a construção da Pedagogia Histórico- Crítica, enquanto uma pedagogia que se dirija aos indivíduos reais e não apenas no que diz respeito ao que eles são, mas principalmente àquilo que eles podem vir a ser".

${ }^{1}$ DUARTE, N. Educação escolar, teoria do cotidiano e a escola de Vigotski. Campinas: Autores Associados, 2001.

R. B. E. C. T., vol 6, núm. 2, mai-ago.2013 ISSN - 1982-873X 
A categoria indivíduo para-si é fundamental para a relação entre objetivação e apropriação e entre humanização e alienação, pois está no cerne destas categorias que contribuirá no entendimento do homem como um ser social. Quanto à categoria objetivação, dado o nível de desenvolvimento do gênero humano, esta se diferencia em objetivação em-si (a linguagem, os costumes e os utensílios) e objetivação genérica para-si (a ciência, a filosofia, a arte, a moral, etc.). As objetivações para-si são intencionais e representam a superação do caráter espontâneo, enquanto as objetivações em-si são cotidianas e não intencionais em que o indivíduo se apropria do mínimo de objetivações do gênero humano, apenas necessária para que ele situe em um contexto social (HELLER, 1977).

As atividades do cotidiano caracterizadas pelas objetivações em-si, de forma geral, são determinadas por objetivos prático-utilitários e não exigem questionamentos e reflexões. Para Heller (1977) o desenvolvimento do indivíduo não se efetiva plenamente se sua vida reduzir- se à esfera do cotidiano. Quando isso acontece é porque a própria relação do indivíduo com o cotidiano é uma relação alienada, reduzindo-se os processos de apropriação e objetivação ao nível de genericidade em-si. No entanto, ela alerta que as objetivações genéricas em-si, assim como a estrutura das formas de pensamento e ação da vida cotidiana não podem ser identificadas com alienação, mas se tornam alienadas desde que o indivíduo ou o coletivo são impedidos de se apropriarem das objetivações genéricas para-si que são fundamentais no processo de conscientização da sua própria vida. Nas palavras da autora: "quando o indivíduo não consegue dirigir conscientemente sua vida como um todo, incluída como parte desse todo a vida cotidiana, o que acontece é que sua vida como um todo passa ser dirigida pela vida cotidiana" (HELLER, 1977). Na visão da autora, para a superação desta alienação se faz necessário a apropriação das objetivações para-si representadas pelos conhecimentos provenientes da ciência, filosofia e arte, as entendendo como atitudes teóricas frente à realidade.

"Ciência, arte e filosofia são objetivações genéricas do conhecimento e autoconhecimento humanos. Enquanto conhecimento e autoconhecimento constituem partes integrantes da práxis humana em seu conjunto, mas o são precisamente como "atitudes teóricas" frente à realidade. Inicialmente surgiram das necessidades da vida cotidiana e das necessidades políticas das integrações; mais tarde, diferentemente, se fizeram autônomas como esferas de objetivações específicas, cuja natureza é não possuir uma relação direta com a vida cotidiana particular ou com as necessidades imediatas de integrações. As ciências naturais são utilizadas nas técnicas (ainda que não desde muito tempo), mas não se trata de ter se convertido em ciências naturais graças ao seu uso imediato. Devem seu posto na práxis humana em seu conjunto ao fato de estudar as leis objetivas da natureza relativamente sem outros fins. A filosofia pode converter-se em ideologia de estratos sociais, pode 
ajudar ao particular [homem] organizar sua própria vida. Contudo a filosofia nesta altura de sua função - e somente por isto pode converter-se em ideologia ou dar uma forma de vida - por que seu conteúdo não se esgota em servir a objetivos determinados, mas por que é capaz de dar aos problemas vitais de uma determinada época, de um determinado movimento social, uma forma que corresponde às conquistas obtidas até aquele momento no desenvolvimento dos valores genéricos. [...] através da catarse a obra de arte, tem condições de capturar a vida das pessoas particulares, e, portanto, em tal sentido, de 'ensinar'. Mas pode fazê-lo por que da expressão a autoconsciência do desenvolvimento humano e por que seu fim não é interferir diretamente na vida, o 'educar'. O poder das puras ideologias na definição dos conflitos sociais (falamos aqui da filosofia e da arte no sentido da concepção lukácsiana) deriva precisamente desta ampla perspectiva, desta ausência de particularidade, deste referir-se ao elemento humano em seu conjunto, deste caráter 'teórico' " (HELLER, 1997, p.188-189, tradução livre, grifo da autora).

É nesse contexto teórico que Duarte (2001) defende uma educação escolar como mediadora na formação do indivíduo entre o contexto da vida cotidiana e o contexto não cotidiano da objetivação do gênero humano. É esta postura que o presente trabalho vai adotar ao tentar responder o questionamento: Por que a Filosofia, História e Sociologia da Ciência podem contribuir para a superação de um ensino de ciências prático-utilitário?

\section{As Categorias da Pedagogia Histórico-Crítica e a Prática Pedagógica no Ensino de Ciências}

Uma vez que apresentamos as principais categorias do referencial adotado neste trabalho, esperamos que a possível resposta que será desenvolvida para a questão apresentada nesta comunicação possa contribuir para uma reflexão por parte dos professores e pesquisadores da área de ensino de Ciências e Matemática.

São vários os fatores que entravam o sistema educacional brasileiro, uma das problemáticas é a deformação estrutural do sistema, a ausência de políticas públicas e quando existem não são eficazes, pois são engendradas em um caráter imediatista como, por exemplo, cursos cujas diretrizes pedagógicas são caracterizadas pela racionalidade técnica.

Apesar das pesquisas educacionais (CONTRERAS, 1997; GIROUX, 1997) mostrarem que o modelo da racionalidade técnica não dá conta de um processo formativo de professores que valorizem a singularidade, a incerteza e autonomia da atividade docente, este modelo ainda parece estar presente nos cursos de formação inicial e continuada de professores. Este modelo reforça uma prática docente aplicacionista de ensino e uma intensa prescrição para ensinar 
determinado conteúdo sem se preocupar com a autonomia do professor e o contexto social em que acontece a prática educativa. Este modelo tem sérias consequências para a formação destes professores e para os estudantes que se submeterão a um ensino fortemente baseado na transmissão do conhecimento, no qual o professor é o detentor do saber e o aluno um sujeito passivo no processo de ensino-aprendizagem. Podemos dizer que, esse tipo de prática pedagógica é uma apropriação das objetivações para-si de forma alienada, pois da forma como as políticas públicas conduzem a educação escolar não dá condições para o professor buscar uma formação mais reflexiva e consciente, numa apropriação da sua própria prática pedagógica, ou seja, uma apropriação-objetivação para-si que propicia um conhecimento além do mero produto.

O conhecimento como mero produto, pronto e acabado é repassado na escola para os estudantes, pelos professores, livros didáticos, mídia etc. Um exemplo disso é o ensino das teorias e princípios da Física de maneira mecanizada por meio de equações matemáticas sem demonstração e discussão epistemológica do seu papel na ciência. Muitas das vezes as equações são utilizadas para resolverem problemas práticos, ou meramente de manipulação matemática direcionando a prática educativa a uma concepção prático-utilitária do saber. Como explicitado anteriormente, o conhecimento científico é uma forma de apropriação e objetivação para-si, mas se for ensinado de forma mecanizada constitui uma forma de objetivação para-si alienada, pois não dá oportunidade para o indivíduo entender o processo de formação e construção desse conhecimento, e ainda, os fatores socioculturais que o envolve.

Mesmo com a problemática exposta acima, existem defensores de um ensino de Ciências, especificamente o ensino de Física, que privilegie o cotidiano dos alunos, mostrando através dos princípios e leis da Física "o como funciona" os objetos e as coisas existentes do mundo do sujeito. Essa proposição precisa ser mais bem problematizada, considerando a relação das propostas e as práticas que informam se sustentar neste princípio metodológico.

O discurso da necessidade de aproximar o conhecimento do cotidiano dos alunos já alcançou os próprios materiais didáticos, o que pode ser identificado no trabalho de Franscisco Jr. (2007). Ao analisar temáticas da área de bioquímica em alguns livros didáticos de Química, na categoria "Relações com o dia-a-dia", identifica grande presença de elementos do cotidiano expressos como exemplos de aplicações dos conteúdos químicos, principalmente, com recursos de imagens. $O$ autor destaca haver um exagero de figuras em detrimentos de discussões conceituais dos tópicos; além disso, enfatiza a pouca problematização presente nos livros, em que predominam o uso de imagens e a discussão de algumas curiosidades, tais como a ação de sabões e detergentes na limpeza de gorduras, sem qualquer discussão, por exemplo, dos impactos socioambientais. O autor, ainda indica algo que não é contemplado pela maioria dos livros analisados,

"embora qualquer forma pela qual seja possivel relacionar conceitos químicos com a vida das pessoas mereça destaque, é fundamental uma abordagem do 
conteúdo químico que permita aos estudantes entender melhor e mais verticalmente as múltiplas relações e implicações sociais do conhecimento químico" (FRANCISCO JR., 2007, p.8).

Para Alves (2006) a falta da totalidade presente nos manuais didáticos é uma tendência geral e dominante, sendo resultante da histórica construção da escola pública contemporânea.

“A substituição das obras clássicas pelos manuais didáticos, entendidos ambos como ferramentas do professor, determinou o generalizado aviltamento do conteúdo do trabalho de ensino. As produções de primeira mão, ou seja, às produções originais, expressivas do que de mais significativo a humanidade produziu em termos de ciência e cultura, seguiram-se textos que se apresentam como sínteses acabadas do conhecimento na área respectiva" (ALVES, 2006, p.170).

Outros exemplos são as aplicações dos princípios físicos que permitem explicar o funcionamento de uma televisão, do aparelho de som, o chuveiro elétrico, da usina hidrelétrica etc. Este discurso de aplicar o conhecimento científico para explicar o cotidiano representa uma visão prático-utilitária do conhecimento científico e do ensinar Ciências, o que constitui uma apropriação das objetivações para-si do gênero humano alienada, pois como afirma Giardinetto (1999, p. 104), "portanto, quando se pretende condicionar a aprendizagem escolar aos limites do cotidiano está subliminarmente promovendo uma forma de alienação, estabelecendo-se limites para a apropriação das objetivações para-si [...]"

O ensino de Ciências voltado para o cotidiano do estudante tem a sua importância, pois pode permitir ao indivíduo entender os conceitos científicos apropriados na escola e no mundo em que vive, além de possibilitar o aperfeiçoamento das suas relações de trabalho e consumo. Entretanto, será que esta visão prática utilitária do saber pode contribuir para o indivíduo libertarse do processo de alienação? A priori parece que tal perspectiva é insuficiente, pois não permite ao indivíduo ir além daquilo que está posto a ele, dificultando a formação da sua autonomia.

Não estamos contra um Ensino de Ciências que vise o cotidiano, o problema é a sua supervalorização que tende a ser desumanizador e alienante na prática educativa, pois dificulta o estudante buscar os conhecimentos além do cotidiano próximo, que lhe permita refletir o porquê, a ideologia, a cultura, a política que permeou o surgimento de determinado fato científico. Assim, como nos coloca Saviani (2003), entendemos que o cotidiano pode ser um ponto de partida, mas não um ponto de chegada para a educação escolar.

Diante de tal problemática, qual seria a solução para este problema? Em princípio seria um Ensino de Ciências voltado para a formação de um indivíduo crítico que saiba assumir os seus deveres, cobrar os seus direitos, intervir de forma consciente nas decisões políticas dentro de uma sociedade, entendendo que as relações sociais, inclusive o conhecimento científico, são uma 
construção histórico-social. Assim, é necessário que esse indivíduo se reconheça parte desta história e que ele é mais que um simples objeto alienado no sistema capitalista, mas que pode expressar uma força capaz de mudar essas relações, com intuito de buscar a sua humanização. Segundo Giardinetto (1990, p. 40) é necessária uma ação consciente para que haja a possibilidade de superação da alienação. No entanto, o mesmo alerta:

"A necessária ação consciente não significa a exclusão da alienação. Uma atividade consciente pode ser também alienada. Enquanto atividade é atividade social no seio de relações sociais de dominação que geram alienação. Toda atividade é consciente, pois é humana, é dirigida por fins idealmente presentes na consciência. A questão é que essa atividade consciente pode apontar para a humanização do indivíduo ou para a perpetuação da sua alienação. A formação do indivíduo pode apontar para sua humanização se sua individualidade cooptar as possibilidades historicamente produzidas de objetivação consciente, social, livre e universal. Do contrário pode apontar para sua crescente alienação".

\title{
A filosofia, história e sociologia da ciência e a visão prática utilitária do saber
}

Acreditamos, pois, que a utilização da HFSC no ensino de Ciências, desde que não seja apropriada em função das relações de dominação, possa apontar para humanização do indivíduo e contribuir para a superação da alienação. De acordo com Matthews (1995 p.165):

\begin{abstract}
"A história, a filosofia e a sociologia da ciência podem humanizar as ciências e aproximá-las dos interesses pessoais, éticos, culturais e políticos da comunidade; podem tornar as aulas de ciências mais desafiadoras e reflexivas, permitindo, deste modo, o desenvolvimento do pensamento crítico; podem contribuir para um entendimento mais integral da matéria científica, isto é, podem contribuir para a superação do "mar de falta de significação" que diz ter inundado as salas de aula de ciências, onde fórmulas e equações são recitadas sem que muitos cheguem a saber o que significam".
\end{abstract}

Segundo Dias (2001), a história é o foro no qual a análise conceitual pode ser feita, pois permite rever conceitos e criticá-los, recupera significados e os entende à luz de novas perspectivas. A História da elaboração de um conceito mostra não somente como o conceito foi criado, mas, sobretudo, seu porquê. Revela o que o conceito faz na teoria, sua função e seu significado. Revive os elementos do pensar de uma época, revelando os ingredientes com que o pensamento poderia ter contado na época em que determinada conquista foi feita. 
Muitos autores (PORLAN et. al; 1998; HARRES, 1999; KOHNLEIN; PEDUZZI, 2002; MASSONI; MOREIRA 2007; SILVA; MOURA, 2008) por meio de pesquisas na área de Ensino de Ciências e Matemática têm mostrado que estudantes, livros didáticos, meios de comunicação e a formação de professores apresentam uma visão de ciência empirista-indutivista que tenta ficar isenta das influências econômicas, políticas, sociais e culturais. Nesta perspectiva, o principal objetivo dos cientistas parece ser descobrir leis naturais e verdades constituídas de teorias absolutas, isoladas do contexto externo. Tais pesquisas vêm mostrando também, através de estudos históricos e da utilização de referenciais da Filosofia da Ciência contemporânea, que esta visão de ciência é equivocada.

Como forma de superação desta visão predominantemente empirista-indutivista, os referenciais da Filosofia da Ciência Contemporânea são defendidos por pesquisadores da área de educação científica para que sejam inseridos como fundamento do Ensino de Ciências, visando alcançar os estudantes da Educação Básica, os cursos de formação de professores, livros didáticos e a divulgação da ciência de forma geral para que possam ter uma visão de ciência mais próxima da epistemologia contemporânea. No entanto, existem alguns autores como Acevedo et al. (2005) que fazem algumas críticas a esta corrente de pensamento para os quais a Filosofia da Ciência Contemporânea representada por autores como Kuhn, Feyerabend, Lakatos, Laudan não leva em conta as questões como a tecnociência ligadas as guerras, o desenvolvimento industrial, a macrociência, as influências políticas no conhecimento científico. Segundo estes autores, não é de costume estudos na área de pesquisa da didática das ciências que contemplem estes elementos de forma articulada.

A carência de estudos nessa vertente é refletida em um levantamento sobre as pesquisas em HFSC em dois eventos da área de ensino de Ciências e Matemática realizado por Queirós et. al (2009). Este estudo permitiu constatar que apesar da dicotomia internalismo e externalismo estar superada nas pesquisas na área de História da Ciência, o que se percebe no quadro atual da linha de História, Filosofia e Sociologia da Ciência (HFSC) e Ensino de Ciências é uma grande quantidade de pesquisas que visam discutir, por meio de estudos histórico-filosófico, a natureza da ciência a partir da construção das teorias científicas (ou seja, em uma perspectiva internalista), com uma grande ausência de pesquisas que buscam na história social os constituintes da construção da ciência.

Uma prática de ensino que vise abordar o uso da HFSC em uma perspectiva internalista de tal forma a explicitar a história de um conceito científico e aproximar os estudantes da epistemologia contemporânea constitui uma apropriação para-si do conhecimento humano que visa superar respectivamente a distorção conceitual e a visão alienante do empirismoindutivismo. Contudo, acreditamos não ser suficiente, pois não dá conta de uma apropriação para-si crítica quanto aos aspectos ideológicos e sociais que permeiam o conhecimento científico. 
Uma alternativa seria o aumento das pesquisas que visem uma postura mais preocupada em compreender a relação entre internalismo e externalismo, em que são consideradas as questões culturais, sociais e os interesses políticos e econômicos que permearam a evolução de um conceito científico. Nesse sentido, o referencial da pedagogia histórico-crítica pode contribuir uma vez que a historicidade é uma das bases desta teoria educacional, pois de acordo com Saviani (2003), para se saber quais são os interesses que impedem e quais aqueles que exigem objetividade, não há outra maneira senão abordar o problema em termos históricos. Para o autor, uma das tarefas da pedagogia histórico-crítica em relação à educação escolar implica no indivíduo procurar reconhecer as condições históricas da produção do saber objetivo, compreendendo suas principais manifestações, bem como as tendências atuais de transformação.

Nesta direção Gurgel e Mariano (2008) apontam que o processo histórico compreendido em suas contradições pode ajudar a desmistificar a imagem do cientista e do tecnólogo como sujeitos exclusivos das áreas do saber e da ação que elaboram o conhecimento científico e técnico de forma mágica. Para os autores é importante que se introduza a História e Sociologia da Ciência no ensino das ciências, sobretudo na formação de professores, pois o estudo histórico-sociológico é um dos meios pelos quais os estudantes podem aprender a reconhecer a Ciência e a Tecnologia como construções humanas, marcadas por sucessos e fracassos, como resultados de complexas condições sociais, culturais, conflitos, diferenças e atitudes, valores e modos de pensar de grupos históricos. Certamente, nessa ótica social e histórica é que os princípios da revolução de Copérnico, as leis de Newton, o pensamento cartesiano, os avanços da Engenharia Genética do século XX, os estudos de Sabin sobre a poliomielite, a lâmpada elétrica de Thomas Edson, a nanotecnologia do século XXI, dentre outros, poderão ser compreendidos e ter significado em seus processos.

Um exemplo de trabalho de HFSC com um foco mais externalista e assumindo uma postura marxista é o trabalho apresentado pelo físico Boris Mijailovich Hessen, no II Congresso Internacional de História da ciência e tecnologia, em 1931, em Londres. O trabalho apresentado por Hessen intitulado: As Raízes Socioeconômicas do Principia de Newton, mostra um estudo do período em que Newton viveu e desenvolveu o seu trabalho científico. Ele enumera os problemas impostos pelo processo de expansão marítima do século XVII, como as necessidades de transportes, os problemas de orientação pelo mar e em terra, a retirada dos minérios das minas, a construção de armas utilizadas para a dominação de outros povos, a questão energética entre outros problemas que preocupavam a ciência e a burguesia da época.

Hessen também explora os interesses técnicos de Newton na época. Ele relata uma carta de Newton escrita em 1669, em que aconselha o seu amigo Francis Aston em sua viagem por vários países da Europa a estudar cuidadosamente os mecanismos de condução dos navios de navegação, examinar atentamente todas as fortalezas, para que encontrasse seu método de construção; a estudar os métodos de obtenção de metais a partir de minérios e conhecer os 
métodos de purificação e extração; também que averiguasse os locais onde havia rios que tinham ouro, certificando-se do método de obter ouro de rios auríferos, mediante amálgama com mercúrio, se permanecia em segredo, ou, já tornara um conhecimento geral. O autor relata que Newton também apresenta preocupação nos processos de transformação dos metais, por exemplo, a transformação de ferro em cobre. Na época existiam muitas pesquisas no campo da alquimia e era um assunto de grande interesse para Newton, que ocupou quase toda a carta (HESSEN, 1993).

O trabalho de Newton, na descrição de Hessen (1993), mostra-nos que o cientista é influenciado por fatores econômicos, o que é contrário a uma visão de cientista como um ser avesso a sociedade, isolado tentando descobrir as leis da natureza. Entretanto, Hessen (1993) adverte que seria uma grande simplificação deduzir diretamente da economia e da técnica os problemas e tarefas estudadas pelos físicos. Tanto é que Marx e Engels criticaram Barth por apresentar um materialismo histórico reduzido somente às questões econômicas. $O$ fato é que fatores econômicos não são os únicos determinantes de teorias, o trabalho individual e coletivo dos cientistas são também afetados por questões políticas, jurídicas, filosóficas, crenças religiosas entre outros.

$\mathrm{Na}$ biologia, encontramos da mesma forma vários estudos associando as questões econômicas, sociais e políticas de determinado período com a construção e/ou sustentação de determinadas teorias que expressam ou sustentam determinados valores ideológicos. Um dos casos mais explícitos desta relação entre os interesses econômicos e o estudo dos animais e plantas foi a criação dos jardins botânicos, no início do século XVI. Eram importantes centros de atividade científica responsáveis pela organização das expedições científicas e divulgação das descobertas dessa época. Tiveram também a importância de organizar o material trazido do novo mundo para fins estratégicos, econômicos e geopolíticos (AMAZONAS, 2009).

Por um lado a reordenação desses animais e plantas passou a ser uma das principais preocupações desse período com a qual se buscava saber qual era a origem de todos aqueles seres. Por outro lado, o estudo desses novos animais e plantas poderia apresentar um grande lucro aos reis e comerciantes que financiavam as expedições da época (AMAZONAS, 2009).

As viagens organizadas no século XVIII, por exemplo, se preocupavam sobremaneira em descrever os fenômenos observados, os quais seguiam regras estritas, havendo grande cuidado em comprovar os dados obtidos em cada viagem (RAMINELLI, 1998). A própria viagem de Darwin, como naturalista, no Beagle, como a de outros tantos viajantes naturalistas interessados em pesquisa das regiões do novo mundo, era orientada por interesses estratégicos e comerciais da coroa britânica, como, por exemplo, as ilhas Falkland (SALGADO-NETO; SALGADO, 2010). A própria construção teórica da teoria evolutiva de Darwin possuía raízes no liberalismo econômico britânico da época, principalmente de fundo malthusiano (MAGALHÃES, 2007). 
Desta forma defendemos que uma abordagem da HFSC que contemple os aspectos internalistas e externalistas, como nos exemplos de pesquisa citados no campo da Física em relação aos interesses socioeconômicos do trabalho de Newton e no desenvolvimento de alguns episódios da Biologia, pode contribuir para uma apropriação para-si do conhecimento científico produzido pelo homem ao longo de sua história, de tal forma a diminuir o processo de alienação. Isto acontece porque o indivíduo ao estudar as ciências como a Física, a Biologia, a Química, a Geologia, a Matemática, além de entender o formalismo matemático e os conceitos científicos, poderá compreender os fatores ideológicos, políticos, econômicos e religiosos que permearam a formulação de um conceito científico ou a criação de uma tecnologia. Esta abordagem mais ampla da HFSC não garante, mas pode contribuir para uma formação de um indivíduo para-si que compreenda as relações de dominação do seu objeto de estudo (a ciência) e da sua própria existência enquanto indivíduo que objetiva-se e apropria-se em um processo dialético em busca da tão clamada humanização não alienante.

\section{Considerações Finais}

A questão que propomos a responder no decorrer desta comunicação do porquê da HFSC contribuir para a superação de um ensino de ciências prático-utilitário pressupõe um objetivo e uma prática educacional libertadora. Tal concepção libertadora de educação científica é aquela que apresenta possibilidades para o indivíduo se apropriar do conhecimento científico e clássico que desvele as ideologias que o permeia. De acordo com Saviani (2003) o saber é condição necessária para a libertação. Nesta ótica a pergunta que fazemos é que tipo de saber pode contribuir para a libertação do indivíduo? Especificamente que saber proporcionado pela HFSC poderá contribuir para uma educação científica libertadora?

Em nossa argumentação, vimos que uma Filosofia e História da Ciência que contemple mostrar o processo de construção de conceitos científicos, ou discussão de uma natureza da ciência baseada somente na epistemologia contemporânea são insuficientes para uma apropriação e objetivação para-si do conhecimento científico. Pelo menos, diríamos que ela é parcialmente alienante, pois embora possa ajudar a desmistificar a visão de ciência e seu ensino, não dá conta de desvelar os condicionantes culturais, sociais e políticos que influenciam o conhecimento científico.

Uma alternativa seria uma prática pedagógica que mostre aos estudantes que a construção de um conceito científico não é neutro e nem absoluto, mas influenciado pela cultura de uma época, por interesses econômicos, políticos nos quais a produção do conhecimento científico está inserido. Um conhecimento apropriado dessa maneira poderá conduzir a uma objetivação para-si não alienante. 
Neste caso, a aproximação da HFSC como elemento epistemológico no Ensino de Ciências que apresente de forma ponderada as abordagens internalista e externalista no processo de construção de um episódio científico é uma maneira de termos uma objetivação e apropriação libertadora. O conhecimento histórico filosófico e sociológico que aborde os elementos internalistas e externalistas de forma complementar abre um leque de possibilidades para o indivíduo entender não somente os aspectos lógicos e metafísicos do conhecimento científico, mas também os interesses ideológicos e as formas de expressão de cultura que formaram os sistemas científicos e sociais. Neste sentido, o mundo das possibilidades é aberto para o entendimento de que as transformações produzidas pelos seus antepassados foram e são uma transformação humana, que teve influências econômicas e políticas em um processo dialético que fizeram ao longo do tempo as relações sociais se tornarem desumanas e alienantes. Ao perceber isso, ele poderá começar a refletir a sua própria prática cotidiana, na escola, no mundo do trabalho e construir, ao longo do tempo, uma consciência da sua própria realidade, propiciando uma verdadeira busca da sua individualidade libertadora.

Nossa argumentação vai ao sentido de trazer essa questão da necessidade do ensino e da apropriação do conhecimento científico considerando um desvelamento de seus elementos lógicos e formais, mas articulados com aqueles contextuais (da história social). Este é um caminho a ser percorrido pelas pesquisas na área de educação científica e atividades educativas escolares, pois como o estudo de Queirós et al. (2009) aponta há pouco produzido neste sentido até o momento.

Assim como Santos e Caluzi (2005) colocam, há a necessidade de materiais e livros didáticos que reconstruam não apenas os conceitos científicos, mas as lutas sociais que estão por trás deles. Acrescentamos que, além dos materiais didáticos, estas questões estejam presentes na formação dos profissionais que se envolvem com a Ciência, seu ensino ou sua prática. Um aumento de pesquisas nesta direção seria de grande significado para uma apropriação e objetivação para-si do indivíduo para-si, mais libertadora e humanizadora no ensino aprendizagem das ciências.

Mais do que dar uma resposta fechada para a questão "Por que a Filosofia, História e Sociologia da Ciência podem contribuir para a superação de um ensino de Ciências práticoutilitário?" precisamos resgatar na História e tomar as compreensões sobre a imbricada relação entre o ser humano, o ambiente, o seu tempo, os instrumentos e conhecimentos produzidos neste contexto, assumindo como uma ferramenta epistemológica e pedagógica para a construção da visão de mundo. Este resgate não deve ser parte de preocupações restritas aos historiadores, mas também dos educadores que podem, articulando este conhecimento em sua prática pedagógica, contribuir para que seus alunos construam uma compreensão mais ampla da sociedade em que vivem, e para que sejam capazes de criticá-la e buscarem caminhos para sua transformação. 


\section{Referências}

ACEVEDO, et al. Mitos da didática das ciências acerca dos motivos para Incluir a natureza da ciência no ensino das ciências. Ciência \& Educação, Bauru, v. 11, n.1, p. 1-15, 2005.

ALVES, G. L. A produção da Escola Pública contemporânea. 4 ed. Campinas: Autores Associados, 2006.

AMAZONAS, M. de C. Jardins botânicos: valores estratégicos ecológicos e econômicos. Ciência e cultura, v. 62, n.1, p.42-46, 2009

BRASIL. Lei de Diretrizes e Bases da Educação Nacional, no 9394, de 20 de dezembro de 1996.

BRASIL, Ministério da educação, Secretaria de Educação Média e Tecnológica. Parâmetros Curriculares Nacionais: Ensino médio. Brasília: Ministério da Educação, 1999a 364p.

BRASIL, MEC, INEP, Matrizes Curriculares de Referência para o SAEB. Maria Inês Gomes de Sá Pestana et al.. 2 ed.. Brasília: Instituto Nacional de Estudos e Pesquisas Educacionais, 1999b.

BRASIL. Ministério da Educação - Proposta de Diretrizes para a Formação de Professores da Educação Básica em Nível Superior. Brasília, Fevereiro de 2002.

CONTRERAS, J. La autonomia del profesorado. Madrid: Morata, 1997.

DIAS, P. M. C. "A (Im) pertinência da História ao aprendizado da Física (um estudo de caso)", Revista Brasileira de ensino de física, v. 23, n. 2 p. 226-235, 2001.

DUARTE, N. Educação escolar, teoria do cotidiano e a escola de Vigotski. Campinas: Autores Associados, 2001.

FRANCISCO JUNIOR, W. E. Bioquímica no ensino médio?! (De)limitações a partir da análise de alguns livros didáticos de química. Ciência \& Ensino, vol. 1, n. 2, jun. 2007

GIARDINETTO, J. R. B. Matemática escolar e matemática da vida cotidiana. Campinas, SP: Autores Associados, (Coleção polêmicas do nosso tempo; v. 65), 1999.

GIROUX, H. A. Os professores como intelectuais: rumo a uma pedagogia crítica da aprendizagem. Porto Alegre: Artmed, 1997. 270p.

GURGEL, C. M. A; MARIANO, G. E. Concepção de neutralidade e objetividade da ciência e tecnologia na formação de professores de ciências: argumentos para a inserção da história e sociologia da ciência na construção do conhecimento científico. Revista Brasileira de ensino de ciências e Tecnologia, v. 1, n.1, 2008.

HARRES, J. B. S. Concepções de professores sobre a Natureza da Ciência. 1999. Tese (Doutorado em Educação) - Faculdade de Educação, Pontifícia Universidade Católica do Rio Grande do Sul, Porto Alegre, 1999. 
HELLER, A. Sociologia de la Vida Cotidiana. Tradução de José-Francisco Ivars e Enric Pérez Nadal. Barcelona: Ediciones Península, 1977.

HESSEN, B. As raízes sócio-econômicas dos Principia de Newton. In: Gama, R. (Org.) Ciência e técnica. Antologia de textos Históricos. São Paulo: T. A. Queirós Editor, LTDA, 1993, p.30-89.

KOHNLEIN, K. J. F; PEDUZZI, L. O .Q. Sobre a concepção empiristo- indutivista no ensino de ciências. In: Encontro de Pesquisa em Ensino de Física, 8, 2002, Águas de Lindóia. Atas... São Paulo: Sociedade Brasileira de Física, 2002. 1 CD-ROM.

MAGALHÃES, G. A evolução das espécies: da natureza ao liberalismo econômico. Revista de História Comparada, v. 2, p. 295-307, 2007.

MATTHEWS M. R. História e Ensino de Ciências: A tendência Atual de Reaproximação. Caderno Catarinense de Ensino de Física. V. 12, n3, p.164-214, 1995.

MASSONI, N. T; MOREIRA. M. A. O Cotidiano da Sala de Aula de uma Disciplina de História e Epistemologia da Física para Futuro Professores. Investigações em Ensino de Ciências, v.12, n. 1, p. 7-54, 2007.

PORLÁN, A. et al. Conocimiento profesional y epistemología de los profesores, II: estudios empíricos y conclusiones. Enseñanza de las ciencias, Barcelona, v. 16 n. 2, p.271-288, 1998.

QUEIRÓS, W. P.; BATISTETI, C. B.; JUSTINA, L. A. I.; A. Tendências das pesquisas em História e Filosofia da Ciência e Ensino de Ciências: O que o ENPEC e o EPEF nos Revelam? In: MORTIMER, Eduardo Fleury (Org.) VII Encontro Nacional de Pesquisa em Educação em Ciências. Atas... Florianópolis: Associação Brasileira de Pesquisa em Educação em Ciências (ABRAPEC), 2009.

RAMINELLI, R. J. . Ciência e Colonização. Revista Tempo, Niteroi, v. 7, p. 5-28, 1998.

RICARDO, E. C.; ZYLBERSZTAJN, A. Os parâmetros curriculares nacionais para as ciências do ensino médio: uma análise a partir da visão de seus elaboradores. Investigações em Ensino de Ciências, v.13, n.3, p.257-274, 2008

SALGADO-NETO, G.; SALGADO, A. A experiência civilizatória de Jeremy Button Revista de Ciências Humanas, Florianópolis, Volume 44, Número 1, p. 249-259, Abril de 2010.

SANTOS, C. S; CALUZI, J.J. História da ciência e ensino de ciências: a visão externalista. In: CALDEIRA, A. M. A; CALUZI, J. J. (Orgs.) Filosofia e História da Ciência: contribuições para o ensino de ciência. Ribeirão Preto: Kayros Editora, 2005, p. 103-114.

SAVIANI, D. Pedagogia Histórico-Crítica. Campinas: Autores Associados. 2003

SILVA, C. C; MOURA, B. A. A natureza da ciência por meio do estudo de episódios históricos: o caso da popularização da óptica newtoniana. Revista Brasileira de Ensino de Física. v. 30, n. 1, p. 1602-1-1602-10, 2008.

R. B. E. C. T., vol 6, núm. 2, mai-ago.2013 ISSN - 1982-873X 
SILVA, D. B. R.; LOPES, A. R. C. Competências nas políticas de currículo: recontextualização pela comunidade disciplinar de ensino de física. Revista Brasileira de Pesquisa em Educação em Ciências, Vol. 7, n.1, 2007.Disponível em http://www.fae.ufmg.br/abrapec/revistas/V7N1/v7n1a3.pdf Acessado em 19 de outubro de 2010.

Wellington Pereira de Queiros - Graduação em Licenciatura em Física pela Universidade Federal de Goiás (2005), graduação em Bacharelado Em Física pela Universidade Federal de Goiás (2002), Mestre em Física na linha de biofísica pela Universidade Federal de Goiás (2005), Doutor em Educação para a ciência (Ensino de Física) pela Universidade Estadual Paulista (UNESP-Bauru) com estágio Sanduíche no Programa de Pós Graduação em Educação Científica e Tecnológica da Universidade Federal de Santa Catarina (UFSC). Atualmente a principal linha de pesquisa é História, Filosofia e Sociologia da Ciência no Ensino de Ciências, especificamente na Formação Inicial de professores de Física e na docência universitária. É professor da Universidade Estadual de Goiás (UNUCET- Anápolis) e da Universidade Alfredo Nasser (UNIFAN). Atua também na Educação a Distância (EAD). Email: wellington fis@yahoo.com.br

Antonio Fernandes Nascimento Júnior - Graduação em Ciências Biológicas pela Faculdade de Filosofia Ciências e Letras Barão de Mauá (1974), Mestrado em Ciências (Ciências Biológicas) pela Universidade de São Paulo, USP, Brasil (1981), Doutor em Ciências Biológicas (Genética) [Rib. Preto] pela Universidade de São Paulo em 1985 e Doutor em Educação para a Ciência, Faculdade de Ciências da UNESP campus Bauru-SP em 2010. Atualmente é professor adjunto da Universidade Federal de Lavras, Departamento de Biologia. Tem experiência na área de Ensino de Biologia, com ênfase em História e Filosofia da Biologia, atuando principalmente nos seguintes temas: educação ambiental, ensino de biologia, produção de material alternativo, jogos pedagógicos e ensino de etologia. Email: toni nascimento@yahoo.com.br

Daniele Cristina de Souza - Graduação em Ciências Biológicas pela Universidade Paranaense (2006), Mestre em Ensino de Ciências e Educação Matemática pela Universidade Estadual de Londrina (2010). Doutoranda em Educação para a Ciência no Programa da Faculdade de Ciências da UNESP campus Bauru. Atualmente é Professora bolsista no Departamento de Educação Unesp-Botucatu. Professora colaboradora voluntária no Projeto PIBID, UNESP-Bauru. Desenvolve atividades de formação inicial e continuada em Educação Ambiental no Programa Núcleo de Ensino, Unesp-Bauru. Tem experiência na área Educação científica, com ênfase em Ensino de Biologia e Educação Ambiental. Atuando principalmente nos seguintes temas: educação ambiental, ensino de ciências, produção de material didático-pedagógico, divulgação científica, história e filosofia da Biologia. Email: danicatbio@yahoo.com.br 